\title{
Lancaster Postgraduate Statistics Centre - creating enterprise and innovation in teaching statistics across disciplines
}

Gillian Lancaster

Director

Postgraduate Statistics Centre

g.lancaster@lancs.ac.uk

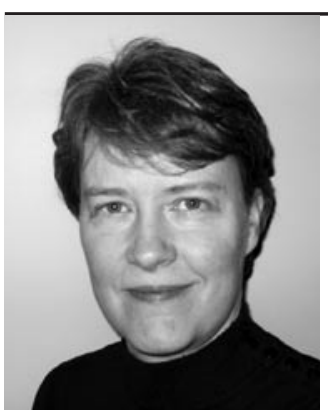

Brian Francis

Deputy Director

Postgraduate Statistics Centre

b.francis@lancs.ac.uk

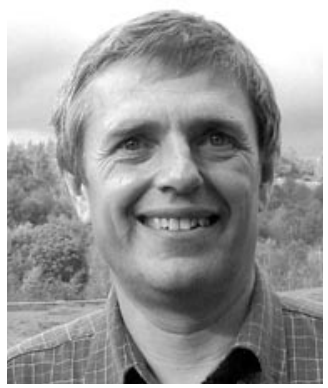

Ruth Allen

Project Facilitator

Postgraduate Statistics Centre

r.allen1@lancs.ac.uk

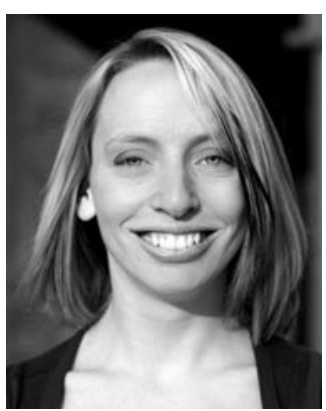

\section{Summary}

The Lancaster Postgraduate Statistics Centre (PSC) encompasses all aspects of Postgraduate Teaching and Learning within the Mathematics and Statistics department. It is the only UK HEFCE-funded Centre for Excellence in Teaching and Learning that uniquely specialises in postgraduate statistics, and rewards the research and teaching excellence of the Statistics Group. The award-winning purpose-built PSC building opened in February 2008, and features many modern state of the art facilities. Our popular MSc courses and short course programme provide excellent training for those wishing to further their knowledge of statistics. We hold regular Teaching and Learning Seminars that focus on innovative teaching methods and technologies, and offer a visiting fellow scheme as well as specialist training at all levels through master classes and workshops run by experts in the field. This article describes the work of the PSC as we proceed past the third year of grant funding. For more information about activities in the Postgraduate Statistics Centre please see our website at http://www.maths.lancs.ac.uk/psc.

\section{Background}

About ten years ago the Government became concerned about the shortage of supply of skills in science, technology, mathematics (including statistics) and engineering, and that this shortage in the supply of high quality scientists may constrain the UK's future Research and Development innovation programmes. This shortage was seen all the way through from school to Higher Education. The Government commissioned a review called 'SET for Success', led by Sir Gareth Roberts, which was published in April 2002 [1]. The review highlighted the shortage in students taking numerical subjects, a lack of women taking ' $A$ ' level science subjects and poor experiences in the education of students in science and engineering. In addition postgraduate education did not lead to the development of the transferable skills required by employers and yet this level of education was fundamental to the development of the highest level of skills. These finding were being reiterated elsewhere. In the International Review of Mathematics in the UK, published in 2004, it was stated that "MSc programs in Statistics are of major benefit for both industrial and university sectors in the UK, but are perennially under threat. They should enjoy greater security and support." [2].

About the same time the Higher Education Funding Council of England (HEFCE) was about to launch its largest ever single funding initiative in Teaching and Learning, amounting to $£ 315$ million over 5 years. The idea was to create 74 Centres for Excellence in Teaching and Learning (CETL) in a wide range of subject areas with two 
main aims, (i) to reward excellent teaching practice and (ii) to further invest in that practice so that CETL funding delivered substantial benefits to students, teachers and institutions. The successful Lancaster CETL bid emphasised the belief that research quality and research-led teaching is crucial in teaching postgraduate statistics specialists. We have found that well-trained Masters students provide a rich source of doctoral students in statistics. This in turn produces highly trained research statisticians and begins to address the current shortage of young statisticians in the public and private sectors.

\section{New state of the art teaching facilities}

The award has partially funded, together with $£ 1$ million of University money, a $£ 3.3$ million building to expand the postgraduate activities of the department and provides state of the art new teaching space. Environmental issues are taken seriously, and the building, designed by architects John McAslan, conforms to the highest environmental assessment rating (BREEAM excellent). The site for the building occupies a unique location within the University. Sitting within a newly formed landscaped area containing a wild flower garden, this area links the existing buildings of Fylde and Furness Colleges with their new residences adjacent to the perimeter road. The north face of the building is glazed and gives views out to the landscaped space and good views of general activity on campus from the new residences to the hub area close to the shops and student union. There is also a water feature that runs the length of the north side of the building that allows natural drainage of rainwater from both the site and from the building itself (Figure 1). The south face has louvred solar protection to cut out direct sunlight and incorporates solar chimneys that promote passive ventilation of teaching spaces by recovering and re-circulating the building's warmth to keep rooms cool in summer and warm in winter.

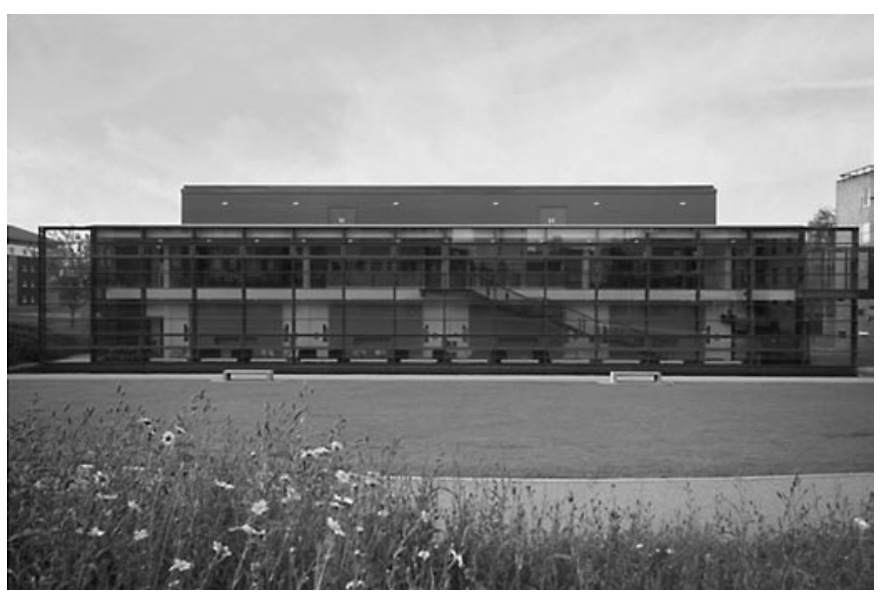

Fig 1 - North facing elevation of the Postgraduate Statistics Centre

On the ground floor of the building there is a large foyer with high and low level seating, a new 50-seat lecture theatre with video and podcasting facilities, that allow teaching to reach beyond the traditional lecture room environment, and a Personal Response System (PRS) system has also been purchased. In addition there is an access grid room for distance teaching to other universities, two computer labs offering a mixture of Windows and Linux environments to suit modern teaching and a small teaching room. The first computer lab contains 24 fixed server clients laid out in rows, and the second room is designed as flexible teaching space for staff to experiment with layout for different teaching styles and has available 35 laptops, with the possibility of expansion into the small teaching room via a sliding wall. A bridge links the existing department to the first floor. On the first floor as well as 10 offices, a kitchen and postgraduate library there are two open-plan social learning spaces to promote informal interaction between academic staff and postgraduate students, where they can drink coffee and discuss work, or study more formally at tables (some portable). There is also a meeting room and consultancy suite which provides one to one mentoring to postgraduates from other disciplines as well as providing training opportunities for our own students. Photographs of the new building can be found on our website.

The new building was officially opened by Professor Sir David Cox on February 21st 2008 (Figure 2). The opening ceremony was well-attended by over 100 guests, that included the Chancellor of the University, Sir Chris Bonington, and Vice Chancellor, Professor Paul Wellings, who all enjoyed a day of planned activities and displays to raise awareness of our work.

Fig 2 - The Postgraduate Statistics Centre was opened by Professor Sir David Cox, former president of the Royal Statistical Society

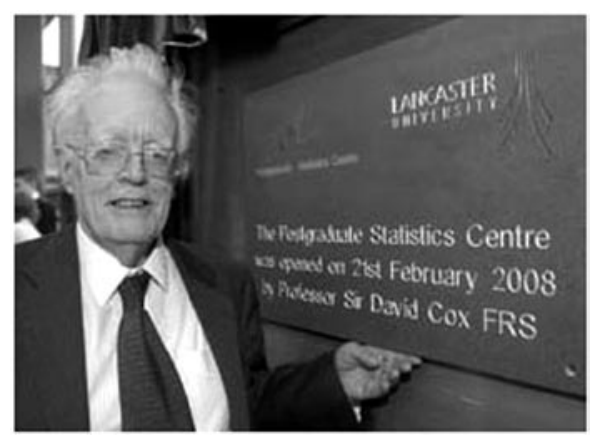

\section{Postgraduate Statistics Teaching and Learning}

The Lancaster Postgraduate Statistics Centre (PSC) uniquely specialises in postgraduate statistics teaching. The funding of the PSC has provided seven new academic members of staff, all of whom are integrated into the departmental structure in traditional academic posts, but with a stipulated special interest in teaching and learning. There are also five support staff consisting of the Project Facilitator, part-time Research Associate, web officer, part-time IT technician and PSC secretary. The integration of the academic posts within the Mathematics and Statistics department enables everyone in the Statistics Group to participate in PSC Teaching and Learning activities. The PSC therefore encompasses all aspects of postgraduate statistics teaching and learning within the department and everyone has the opportunity to get involved in teaching innovation. 
The core aim of the PSC is to achieve excellence in teaching postgraduate statistics, with a specific focus on the development and promotion of postgraduate statistics both within the discipline of statistics and more broadly in other areas. The strategic aim is to become an international centre of excellence, through development of new MSc modules and programmes, increased service level teaching, and an expanded short course programme, by working with colleagues within the university and external professional bodies. The five core aims of the PSC are summarised as follows:

1. To become a regional, national and international centre of excellence in the PG training and development of statisticians

2. To motivate, encourage and provide quantitative inquiry-led training for students from other disciplines eg. natural, social and management sciences

3. To give Lancaster trained postgraduate students in all disciplines enhanced quantitative skills which will influence their whole approach to research

4. To develop critical thinking in the use of statistics at a level appropriate for each group of students

5. To reward existing excellence in postgraduate teaching

By fulfilling these aims the PSC brings exceptional benefits to the university in ensuring that substantial investment goes directly into innovative teaching and learning so that both current and future users of statistics, supported by excellent, motivated teachers, can look forward to an inspiring, challenging and worthwhile learning experience.

\section{Benefits of the PSC to Teachers and Learners}

An overview of the structure and function of the PSC is given in Figure 3, which shows how the key activities (the squares) are upheld by four underlying elements - staffing and management, awareness and publicity, finance and evaluation (the arrows) that give a supporting structure across all activities, and which together form our basis of sustainability.

The aims of the PSC are underpinned by ten strategic objectives that focus primarily on, the extension and enhancement of existing opportunities for postgraduate students studying statistics, the provision of topical and motivational postgraduate training programmes and through provision of Continuing Professional Development opportunities for staff, external professionals from the public and private sectors, and visiting fellows from overseas institutions. Whilst the majority of our work has already been described in a previous publication [3] the most up to date activities have been briefly summarised below under each objective.

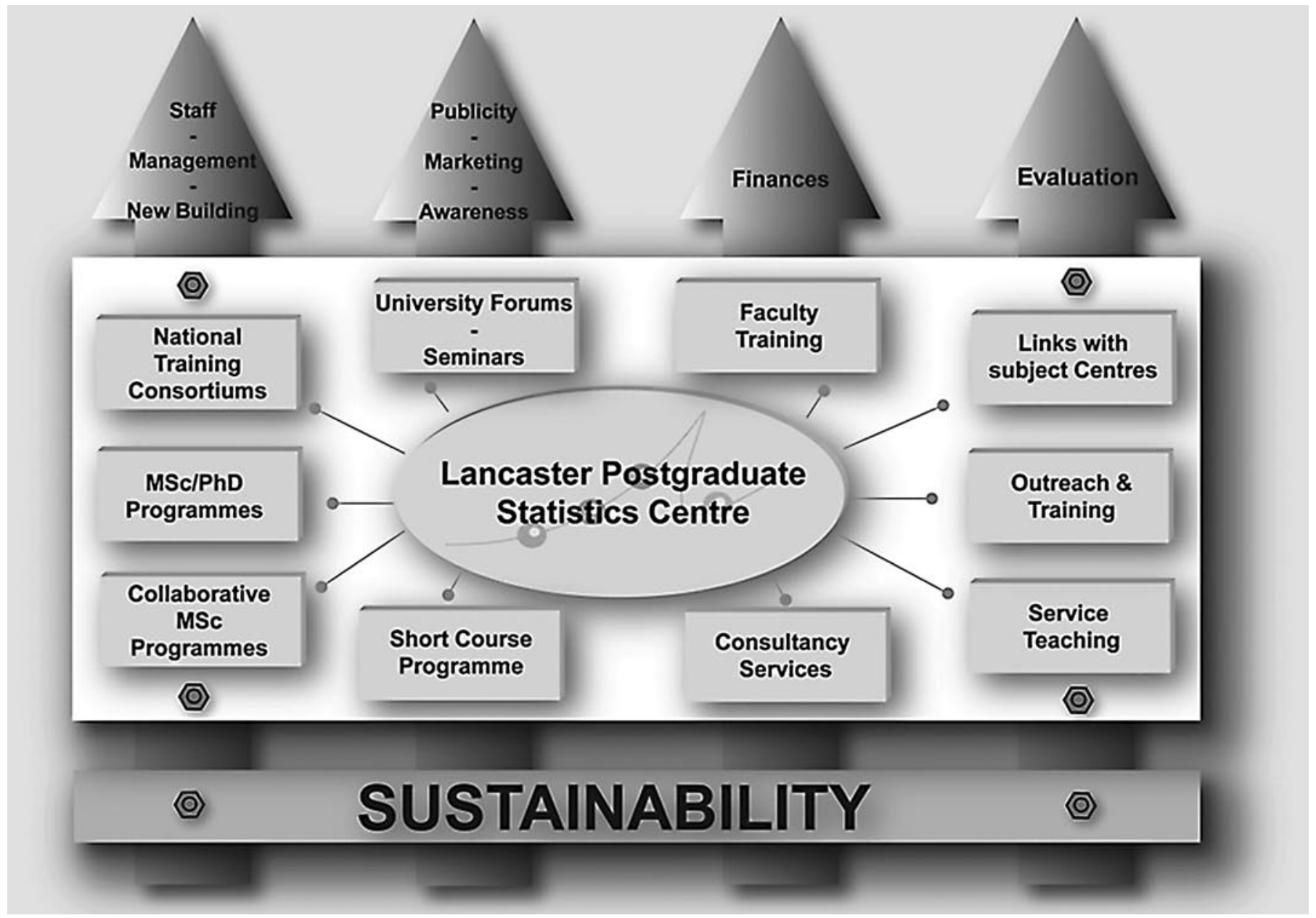

Fig 3 - Structure and function of the PSC 


\section{To extend and enhance existing opportunities for postgraduate statistics students.}

The CETL funding has enabled us to develop and strengthen our existing MSc programmes, which in turn enables us to promote a contemporary perspective and provides a natural synergy of past and present activities. With our strong track record of high quality and innovative statistics teaching combined with our increased capacity for delivering new postgraduate statistics modules, we are able to attract exceptionally high-quality students to study on our MSc courses. We have restructured a new MSc in Statistics for 2008/09 with pathways in Medical Statistics, Pharmaceutical Statistics and Environmental Statistics, and also have added new modules to the MSc in Applied Social Statistics and Masters in Research in Applied Social Statistics. These programmes as well as the Integrated $\mathrm{PhD}$ programme that we offer provides a rich source of postgraduate research students, which in turn brings in extra income for the university.

\section{"The CETL funding has enabled us to develop and strengthen our existing} MSc programmes, which in turn enables us to promote a contemporary perspective and provides a natural synergy of past and present activities."

\section{To expand our innovative style of inquiry-led statistics teaching into other disciplines.}

Initiatives to develop knowledge transfer partnerships with internal and external clients are important. PSC staff are giving a high priority to addressing the demands of end users when engaged in third mission activities, in addition to fulfilling the CETL remit to increase and deepen the impact of excellent statistics teaching practice across the sector. We are finalising our new MSc agreement with Lancaster University Management School (LUMS) for a joint MSc programme in Quantitative Finance. We contribute to Faculty Training programmes for PhD students and to expanded MSc modules for service courses in five departments. Our short courses and consultancy service have also been expanded. Extension of the service already offered includes expanding on outreach activities offered to other departments within the university including the newly restructured Lancaster Environment Centre (LEC), on the role of statistics in research.

\section{To develop innovative biomedical courses within the new Medical School}

Progress has been delayed because of the restructuring of the Department of Medical Education, Institute of Health
Research and part of Biological Sciences into a new School of Health and Medicine, which opened in September 2008. However, training in the form of an introductory statistics course, prior to statistics consultancy sessions, was successfully piloted to Manchester Medical students at the Royal Preston Hospital and will be repeated this next year.

\section{To develop collaborations with other institutions to provide specialist training}

The synergy of the PSC with other EPSRC and ESRC initiatives reinforces Lancaster's position as a leading national training centre for postgraduate statistics. We engage nationally in the training of postgraduate students in statistics and related skills through several consortiums including the ESRC National Centre for Research Methods (NCRM), ESRC Regional Training Centre, EPSRC National Taught Course Centre in OR (NATCOR), EPSRC Academy for PhD Training in Statistics (APTS) and Mathematical Access Grid Instruction and Collaboration Consortium (MAGIC). The access grid node has been running successfully since February 2008 and, in addition to offering Lancaster's expertise to students from other institutions, has greatly increased the choice of specialist modules on offer to students studying on our undergraduate programmes at Lancaster. A short course was also delivered to Lancaster students, via the access grid node, from the University of Queensland, Australia.

\section{To provide motivational and focussed PG training workshops in a range of disciplines}

We have developed a new Forensic Science Programme and new short courses on Statistical Genomics and Pharmaceutical statistics. We also host specialist conferences; in 2008 these included the CETL/MSOR conference, a 'Probability and Geometry' conference and a meeting on Statistical Extremes. Our ability to participate fully and host conferences is greatly increased due to the new facilities provided in the PSC building and the administrative support provided by the PSC facilitator.

\section{To instigate a Master Class programme in emerging substantive areas with visiting experts.}

Some of these have been co-sponsored by the PSC and NCRM and in 2008 included specialist master classes in 'User-interfaces and graphics in R' (Adrian Bowman, Richard Newton), 'Ordinal data analysis' (Alan Agresti), 'Latent class and latent transition analysis' (Linda Collins, Stephanie Lanza and Bethany Bray) and a very popular master class workshop on 'Geospatial software' (Barry Rowlinson, Jason Jorgenson, Virgilio Gómez Rubio and Jo Cook). For 2009 we have classes planned on GAMLSS (GAMS for location, scale and shape - Mikis Stasinopoulos and Robert Rigby) and 'Missing data' (James Carpenter). 


\section{To develop a visiting fellow scheme.}

We have had two visiting lecturers from the Federal University of Parana in Curitiba, Brazil, a visiting lecturer from the University of Tehran, a visiting senior lecturer from Colombo University, Sri Lanka, and we have more visits planned in relation to our master classes.

\section{To expand the use of web-based teaching, video material and on-line datasets}

A range of new resources continues to be developed within the centre. E-learning materials that will enhance the current student experience and enable future distance learning initiatives are already available and continue to be developed further (please see our website for further details). Experimentation with new technological advances in teaching is underway with the use of Personal Response Systems and Computer Based Assessment tests in some MSc modules, video-capture of case studies for use on the consultancy skills course and screen capture scenarios contributing to the development of online courses. Following the many varied activities within the PSC, we are currently reviewing our resources, collecting new ones and creating a teaching resource bank including a DVD library.

\section{To develop teaching excellence in our new statistics lecturers.}

We have introduced mentoring for new staff, together with peer review of lectures with constructive feedback. New staff are encouraged to study for the Lancaster Certificate of Academic Practice and/or the MSOR Statistics Lecturer Training Course. We hold an annual module review day to review feedback. Pedagogical research is actively encouraged and we run a Teaching and Learning Seminar series. There is also IT support for creating web-based teaching material.

\section{To further enhance and reward the teaching excellence of all staff}

Staff reward for excellent teaching is an important part of the HEFCE remit. Our greatest reward is our improved working environment in the new building. In addition teaching innovation points can be awarded as part of staff workload allocations and teaching innovation is recognised in staff appraisals. There are funds for continuing professional development, small grants for course development or innovation and funds for conference travel to promote teaching and learning.

\section{Pedagogical Research and Evaluation Strategy}

In order to maintain our strong teaching and learning record, we place great importance on the role of pedagogic research in informing teaching and learning practice within the PSC. Research into the pedagogy of statistical education was initiated with the appointment of a CETL RA focusing on problem-based learning techniques in providing and promoting transferable skills for statisticians and users of statistics from other disciplines. This work was expanded upon through the initiation of a series of mini projects which started in December 2007 (to continue with a second call for project proposals in January 2009). Six awards of up to $£ 5000$ were allocated in response to the call and the projects are currently being disseminated through peer reviewed publications and international conferences. A key objective of the PSC is to get all staff involved in pedagogical research for the benefit of teaching and learning, and regular Teaching and Learning Seminars as well as CETL Innovation meetings are designed to inspire new ideas, formulate new plans and integrate what we have learnt so far into the teaching and learning strategy of the centre.

\section{"The PSC is committed to addressing the current national shortage of graduates with statistical analysis and quantitative skills by striving to increase the number of funded places available on our MSc and PhD schemes."}

Intrinsic to the teaching and learning pedagogic strategy of the centre, as well as to the effective use of space and usage of the PSC, is the ongoing evaluation of the CETL project. A thorough evaluation plan has been created in collaboration with the Centre for the Study of Education and Training (CSET) and is being implemented continually throughout the duration of the project. Work will include impact studies of the Centre's activities, as well as qualitative research investigating the student experience of studying within the PSC, evaluation of the new state-of-the-art building, and evaluation of the social learning space and how this affects teaching and the learning experience. Meanwhile the continual evaluation of courses offered to students within the PSC, courses offered to external statistics users and service taught courses university wide, will help to maintain the PSC as a leader in innovative postgraduate statistics teaching.

\section{Institutional and National Impact}

We have now laid a firm foundation within the institution and have devised an effective evaluation plan. Sustainability was a key theme at the most recent CETL conference in April 2007 with many CETLs expressing their concerns for the future. It is therefore timely to formulate a plan for integration of the PSC within the department post 2010, and a departmental strategic plan is being devised. Clearly any plan for the future must demonstrate consideration of value for money in the decision-making process and evidence of an income stream. The PSC is committed to addressing the current national shortage of graduates with statistical analysis and quantitative skills by striving 
to increase the number of funded places available on our MSc and PhD schemes. We have shown that the scope for innovative Masters courses combining disciplinary knowledge with targeted quantitative modules is wide ranging. Within the institution we continue to strengthen the statistical foundations of other disciplines by increasing our capacity for delivering new postgraduate statistics modules and by working together with other departments in the joint delivery of courses through team teaching.

The CETL initiative has enabled more dedicated time and impetus to be given to marketing the work of the PSC. In terms of increasing awareness within the university, a CETL Awareness Symposium held in January 2008 to raise the profile of the work of the PSC within the department and to plan activities for the opening ceremony event, was a success and was attended by 34 staff. In addition, a regular CETL news slot has been incorporated into the departmental newsletter. CETL student prizes for excellence in learning were allocated for the second year running to the highest achievers on the MSc programmes on Graduation Day in December 2008. In addition the PSC has hosted and provided support for two new universitywide forums, the Maths Forum and the Statistics Teaching Forum, created to support dyscalculia in students and staff interested in teaching statistics, respectively. We have extended beyond the university to the wider academic community by providing regional and national specialist statistical training courses for postgraduate students and statistics professionals. With the University's recent designation as an ESRC regional training centre, Lancaster has become recognised as a regional and national centre for training people in statistical methodology, for statisticians and non-statisticians alike. Our engagement with national bodies such as the ESRC can only be beneficial in helping to increase the supply of world-class quantitative researchers.

We meet regularly and engage nationally with representatives of other subject specialist bodies including the Royal Statistical Society (RSS) Centre for Statistical Education, the SIGMA CETL [4] and the MSOR network. This has led to a jointly organised Statistical Education session at the 2008 RSS conference and the hosting of the CETL-MSOR conference here at Lancaster in 2008, and at least one of our team regularly sits on the scientific programme committee for the CETL-MSOR conference. By working together with external partners we hope to become an international centre of excellence to promote the role of statistics and statistical thinking for future generations of researchers. Lancaster was awarded the CETL grant as a result of its excellent track record in postgraduate statistics teaching. There is a shortage of professional statisticians and the statisticians of tomorrow are in secondary and higher education today. Continuing professional development is therefore crucial for building and supporting statistical education in schools and higher education. By working together we hope to encourage and invest in a fresh approach to teaching statistics.

\section{References:}

1. SET for success: the supply of people with science, technology, engineering and mathematics skills (2002). Report of Sir Gareth Roberts' review, April 2002, found at http://www.hm-treasury.gov.uk/documents/ enterprise_and_productivity/research_and_enterprise/ ent_res_index.cfm

2. International Review of Mathematics in the UK (2004), http://www.cms.ac.uk/irm/index.html.

3. Abrams B. and Francis B. (2007). Introducing the Lancaster Postgraduate Statistics Centre - a Centre of Excellence in Teaching and Learning (CETL). MSOR Connections, 7 (2), 11-15.

4. Croft A., Lawson D., Hawkes T. and Petrie M. Sigma: university-wide mathematics and statistics support - three years on. MSOR Connections, 8 (4), 34-37. 